\title{
Observations On The Larval Rearing Of Macrobrachium rosenbergii (De Man) By Using Artemia Nauplii And Egg Custard As A Feed In Different Combinations
}

\author{
Dr. M. Shailender ${ }^{1}$, Suresh Babu. $\mathrm{Ch}^{2}$, Srikanth, $\mathrm{B}^{3}$ and Krishna, P.V ${ }^{4}$ \\ ${ }^{1,3}$ Rajiv Gandhi Centre for Aquaculture (RGCA), DTSP, Kodiyaghat, South Andaman, India. \\ ${ }^{2,4}$ Acharya Nagarjuna University, Nagarjuna Nagar, India.
}

\begin{abstract}
An experiment was carried out at Department of Zoology and Aquaculture, Acharya Nagarjuna University, India from July to August 2010 to assess the effect of feed on larval survival of Macrobrachium rosenbergii. Three experiments viz. Artemia nauplii plus egg custard (E-1), Artemia nauplii only (E-2) and Egg custard only (E-3) were taken for the study each with two replicates. The experiment was conducted in fiber tanks with Macrobrachium rosenbergii larvae at a density of $100 \mathrm{no}$ lt of water. Highest average survival rate (42\%) was found in E-1 and the lowest survival rate was obtained in E-3. The results obtains that there is a immense potentiality for increasing freshwater prawn seed production through closed water system by using Artemia nauplii plus egg custard as feed.
\end{abstract}

Key Words: Macrobrachium rosenbergii, Artemia nauplii, Egg custard, larval growth

\section{Introduction}

The giant fresh water prawn, Macrobrachium rosenbergii known as "scampi" is available in fresh water and brackish water environment of Andhra Pradesh. The prawn have a long larval history and require some salinity to grow (Ling, 1969 and Fujimura, 1972) but their growth, maturation, gonad development and breeding etc can easily take place in fresh water. The prawn farming in Andhra Pradesh is entirely dependent on hatchery seed. It has more demand than marine shrimp because of availability of seed, low investment and good returns. It has more disease resistance than shrimp. Prawn formers are now facing trouble of culturing the species due to whit muscle syndrome. The technique of prawn seed production have been developed in many countries like Thailand, Vietnam, Indonesia, Malaysia, Sri Lanka, Hawaii, Taiwan, China, Bangladesh and Japan. Ling (1962) was the first pioneer fro successful prawn seed production. Later on, Ling and Merican (1961), Fugimura (1966) and Fujimura and Okamoto (1972) were successful to produce post larva (PL) of fresh water in mass scale Few attempts have been made in Bangladesh to produce seed of M.rosenbergii (Ahmed and Mahmood, 1978; Islam et al., 1983 and Bhuiya et al., 1983). Considering the above circumstances, the present study was undertaken to assess the effect of different types of feed on larval survival of M.rosenbergii.

\section{Material And Methods}

The experiment was conducted in six circular fiber tanks at the hatchery complex of Department of Zoology and Aquaculture, Acharya Nagarjuna University, Guntur, Andhra Pradesh, India during July to August, 2010. The tanks were connected with the help of air compressor and air blower. The tanks were divided and placed under the treatment (E-1, E-2, and E-3) each having two replicates. Construction of larval rearing tanks: A circular conical bottomed fiber tank of 150 lt of water capacity was used as the larval rearing tank. A hole of $2.0 \mathrm{~cm}$ dia was done $8.0 \mathrm{~cm}$ below the upper edge of the rearing tank. A short PVC pipe of $2.0 \mathrm{~cm}$ dia was inserted through the hole at 45 degree angle. The tank was filled with treated saline water of $12 \mathrm{ppt}$. A fine mesh sized screen was fastened to the mouth of the outer through which water could pass only.

\section{Disinfection of saline water and equipment:}

Brackish water of $12 \mathrm{ppt}$ was stored at over head tank through the gravel filter. The eater was kept in the tank for 3-4 days to settle down the suspended particles. The accumulated water was passed through the sand filter and ultra-violet (UV) filter and stored again in the over head tank. Finally the water was treated with bleaching powder (35\% chlorine content) at a dose of $5 \mathrm{ppm}$ for killing the harmful organisms and aeration was provided vigorously for two days to eliminate the smell of chlorine. After $36 \mathrm{~h}$, water was again treated with sodium thiosulphate at a dose of $10 \mathrm{ppm}$ to eliminate the access chlorine and aerated vigorously for 2 days and to keep stable for one day to settle down the suspended particle. This sterilized water was transferred in to tanks for rearing of larvae. The necessary materials such as pipes, gravel, cover and other for hatchery operation were disinfected by soaking in a solution of $15 \mathrm{ppm}$ bleaching powder containing $35 \%$ chlorine content for 12 hour. After 12 hour. All the materials were washed with fresh water to remove the smell of used powder. During the 
culture period, siphoning pipe, bowl, water exchanging nets and others were washed two times with gentle hot water prior to use in the siphoning.

\section{Hatching and larval rearing:}

The berried female were collected from the brood ponds and disinfected for 20 minutes with $10 \mathrm{ppm}$ formalin. The disinfected females were then kept in a aquarium having 6 ppt saline water. The females were hatched after two days of stocking in the aquarium. The females were fed with fresh snail and beef liver at the rate of $10 \%$ of their body weight. After hatching, females were removed from the aquarium, and bottom and other sides of the aquarium were cleaned very carefully and $70 \%$ of the water was removed from the aquarium and added disinfected water. Hatchlings were reared two days in aquarium. Newly hatched larvae were not fed for the first days. After second day hatched larvae were disinfected for $30 \mathrm{~min} 15 \mathrm{ppm}$ formalin bath and then stocked in six rearing tanks each containing $150 \mathrm{~L}$ of 12 ppt water at a density of 100 no per $\mathrm{L}$ for rearing. The larvae of six tanks were under three treatments namely E-1 (Artemia nauplii plus egg custard), E-2 (Artemia nauplii only) and E-3 (Egg custard only). In E-1 the larvae were fed with Artemia (brine shrimp) nauplii thrice in a day at $7.00 \mathrm{am}, 13.00 \mathrm{pm}$ and $18.00 \mathrm{pm}$ for first 8 days. After day 8 , the larvae were fed with prepared feed, egg custard (egg, milk powder= 1:1 and vitamins) twice a day besides Artemia nauplii at the rate of $300 \%$ of the body weight. In case of E-2, the larvae were fed with Artemia nauplii only twice in a day at 9.00 am and 18.00 pm from day 3 to post larval stage. In E-3, the larvae were feed with only egg custard at the same time of E-2 at the rate of $300 \%-100 \%$ of the body weight from the day 3 to post larvae stage. The uneaten feed, moulted shall and other wastes were siphoned out prior to every feeding time. Water quality parameters of culture media like temperature, salinity, alkalinity, dissolved oxygen, $\mathrm{pH}$ and un-ionic ammonia were measured daily basis. The data were statistically analyzed for experiments comparison.

\section{Results And Discussion}

The values of physico-chemical conditions such as like temperature, salinity, dissolved oxygen; alkalinity, $\mathrm{pH}$ and un-ionic ammonia of culture media have been shown in table-1. During the period of study no apparent variation in temperature of rearing media under different experiments was found. The water temperature as recorded was between 27.0-31.5 oC. The salinity $12 \mathrm{ppt}$ was maintained under the three experiments was the same. Dissolved oxygen content of culture media of different treatments was ranged between $5.0-7.5 \mathrm{mg} / \mathrm{l}$. The $\mathrm{pH}$ value was ranged between $7.0-8.2 \mathrm{mg} / \mathrm{l}$ in all the rearing tanks of the experiments. The alkalinity value was ranged between $75-85 \mathrm{mg} / \mathrm{l}$ in all the rearing tanks of the experiments. Un-ionic ammonia content of rearing tanks as recorded was varied between $0.03-0.15 \mathrm{mg} / \mathrm{l}$. The values of different parameters except un-ionic ammonia, alkalinity of the present study were comparatively same stated by Khonhker (1996) and Islam et al., (2000). The level of un-ionic ammonia was somewhat similar with the value described by Ling (1952). The average survival and production of post larvae are presented in Table- 2 . The survival rate of larva was found to vary from $8-42 \%$. Highest rate of survival $(40-42 \%)$ was recorded in experiment E-1 and the lowest rate of survival $(8-10 \%)$ was recorded in experiment E-3. The cause of such variation occurred because of higher nutritive and growth promoting value of egg custard. In E-1 the larvae fed with Artemia nauplii plus egg custard, because in E-3 the larvae fed with only egg custard, which was so nutritive like Artemia nauplii. In E-3 the un-ionic ammonia was also higher than the other experiments.

The result obtained from the present study indicated that rearing of fresh water prawn larvae by improved management technique can be considered economically viable and acceptable. So, the production of post larvae of prawn could be increased significantly by using Artemia nauplii and egg custard as larval feed. This technique would be more useful for culturing prawn larvae in the remote areas where saline water is not available and transportation of saline water is very costly.

Mass mortality was observed in E-3 and E-2 while the larvae attain to metamorphosis to PL stage which might possibly due to the lack of nutrition. The rate of survival obtained from E-1 in the present experiment was higher than the earlier production of $30.0 \mathrm{PL} / 1$ (Islam et al., 2000), $11.93 \mathrm{PL} / \mathrm{l}$ (Islam and Khan, 1990), 10.22 PL/l (Adisukresno et al., 1982) and 9.5 PL/l in closed re-circulated system (Lee, 1982). However, a good performance of Artemia nauplii an d egg custard was also observed by Yambot and Vera Cruza (1986) where the authors found $25.7 \%$ survival for M.rosenbergii larvae which is agreement with the present findings. It was observed that larvae became very active during the age of 20-25 days and stated jump and clung to the wall of the rearing tank and become dead. Similar observation was also reported by Islam et al., (1983). Strong aeration was provided to prevent this jumping tendency.

The result obtained from the present study indicated that rearing of fresh water prawn larvae by improved management technique can be considered economically viable and acceptable. So, the production of post larvae of prawn could be increased significantly by using Artemia nauplii and egg custard as larval feed. This technique would be more useful for culturing prawn larvae in the remote areas where saline water is not available and transportation of saline water is very costly. 


\section{References}

[1] Adisukresno. S., G. L. Escritor, K. Mintardio, 1982. Mass production of Macrobrachium post larvae in the Brackish water Aquaculture Development Centre, Jepara, Indonesia. In: Gaint prawn farming. Elsevier Amsterdam, 143-156 pages.

[2] Ahmad, M. K and N. Mahmood. 1978. On the early embryonic development and hatching of the giant prawn Macrobrachium reosenbergii(de man). Chittagong University studies, part 2: 97-101.

[3] Bhuiyan, A.L., K. S. Islam and Kar, P. R., 1983. Development and transfer of technology of culture of seed s of the giant prawn Macrobrachium rosenbergii (de man) for distributing to prawn farmers. Annual report of BARC research project, Dhaka. Bangladesh. 16 pp.

[4] Das. S. M., 1989. Hand book of limnology and water pollution. South Asian Publishers pvt. Ltd.36 Netaji Subhash Marg. New Delhi.

[5] Fuzimura, T., 1966. Notes on the development of mass culturing techniques of giant prawn Macrobrachium rosenbergii (de man). Proc. IPFC. 12th sess.

[6] Fuzimura. T., 1972. Development of rearing techniques for the giant prawn Macrobrachium rosenbergii (de man). Nat. Mar. Fish. Ser. USA.

[7] Fuzimura. T and H. Okamoto, 1972. Notes on progress made in developing mass culture techniques for prawn Macrobrachium rosenbergii in Hawaii. In Coastal Aquaculture in the Indio- pacific Region. ; Edited by T.V.R Pillay. West Byflect, England, Fishing News Books Ltd., for IPFC/FAO. 313-327 PP.

[8] Islam, K. S., A. L. Bhuiyan and Kar, P. R., 1983. Factor affecting seed culture of Macrobrachium rosenbergii with special reference to salinity tolerance. Chattagang University Studies, Part II 7: 85-89.

[9] Islam, K. S., and Y. S. A. Khan, 1990. Mass production of post larvae of Macrobrachium rosenbergii at the prawn Hatchery and Research Centre. Cox's Bazar, Bangladesh. Bangladesh J. Zoo., 18: 53-59.

[10] Islam, M. S. A Khan nd S. U. Ahmad., 2000. Observations on the larval rearing of Macrobrachium rosenbergii by using different types of feed n Bangladesh costal environment. Pakistan J. Bio. Sci 3 (10): 1790-1792.

[11] Khondhker, H. R., 1996. Glade Cingari Hatchery Management (in Bengali). A fish fortnight compendium. Technologies and management of Fisheries Development. Bangladesh Fisheries Research Institute, Mymensingh, 99-105 pp.

[12] Ling. S. L., 1982. Progress in developing slandered system for the producing juvenile of Macrobrachium rosenbergii at mardi. Maslacca. In: Giant Prawn Farming, Elsevier, Amsterdam, 120-142 pp.

[13] Lee, S. W., 1962. Studies on the rearing of juvenile and culture of adults of Macrobrachium rosenbergii. FAO current affairs bulletin, 35:1-11.

[14] Ling, S. W., 1969. Methods of rearing and culturing Macrobrachium rosenbergii. FAO Fish. Rep., 57 (3).

[15] Ling, S. W. and A.B.O. Merican, 1961. Notes on the life and habits of the adult and larval stages of Macrobrachium rosenbergii. IPFV Proc., 9: 55-61.

[16] Yambot, A. V. and E. M. Vera Cruz, 1986. Larval rearing of Macrobrachium rosenbergii in brine solution and sea salt. In J. L. Maciean, L. B. Dizon and L. V Hosillos (Eds.). The first Asian Fisheries Forum. Asian Fisheries Socoety, Manile, Philippines. $185-188 \mathrm{pp}$.

Table-1: Mean values with range of physico-chemical parameters of the culture media under different experiments

\begin{tabular}{|c|c|c|c|c|c|}
\hline Experiment & Temp (OC) & $\begin{array}{c}\text { Salinity } \\
(\mathbf{p p t})\end{array}$ & $\begin{array}{c}\text { Alkalinity } \\
(\mathbf{p p m})\end{array}$ & $\mathbf{p H}(\mathbf{p p m})$ & $\begin{array}{l}\text { Ammonia } \\
(\mathbf{p p m})\end{array}$ \\
\hline E-1 & $\begin{array}{c}29.5 \\
(29.0-31.5)\end{array}$ & 12 & 75 & 7.8 & 0.03 \\
\hline E-2 & $\begin{array}{c}29.5 \\
(29.0-31.5)\end{array}$ & 12 & 85 & 7.6 & 0.09 \\
\hline E-3 & $\begin{array}{c}29.5 \\
(29.0-31.5)\end{array}$ & 12 & 80 & 8.2 & 0.15 \\
\hline
\end{tabular}

Table-2: Survival rate (\%) and production of Macrobrachium rosenbergii under different experiment

\begin{tabular}{|c|c|c|c|c|c|}
\hline Experiment & $\begin{array}{c}\text { No of larvae } \\
\text { stocked }\end{array}$ & $\begin{array}{c}\text { Stocking } \\
\text { density/L }\end{array}$ & $\begin{array}{c}\text { Rearing } \\
\text { period }\end{array}$ & $\begin{array}{c}\text { \% of } \\
\text { survival }\end{array}$ & $\begin{array}{c}\text { No. of PL } \\
\text { produced }\end{array}$ \\
\hline E-1 & 1500 & 100 & 25 & 42 & 630 \\
\hline E-2 & 1500 & 100 & 32 & 15 & 225 \\
\hline E-3 & 1500 & 100 & 38 & 8 & 120 \\
\hline
\end{tabular}

